\title{
A survey of distance learning in Morocco during COVID-19
}

\author{
Sara Ouahabi ${ }^{1}$, Kamal El Guemmat ${ }^{2}$, Mohamed Azouazi ${ }^{3}$, Sanaa El Filali ${ }^{4}$ \\ ${ }^{1,3,4}$ Modeling and Information Processing Laboratory, FSBM, Hassan II University, Casablanca, Morocco \\ ${ }^{2}$ Signals, Distributed Systems and Artificial Intelligence Laboratory, ENSET, Hassan II University, Mohammedia, \\ Morocco
}

\begin{tabular}{|c|c|}
\hline Article Info & ABSTRACT \\
\hline Article history: & The face-to-face mode is always considered as the normal mode of teaching, \\
\hline Received Aug 11, 2020 & $\begin{array}{l}\text { and distance education is often understood as a remedy for the lack of } \\
\text { material and human resources necessary to conduct training; but to prevent }\end{array}$ \\
\hline Revised Mar 25, 2021 & the spread of the coronavirus (COVID-19), the distance course system has \\
\hline Accepted Apr 12, 2021 & $\begin{array}{l}\text { been launched in different countries to ensure continuity of teaching during } \\
\text { the period when courses are stopped. In order to shed light on the role of }\end{array}$ \\
\hline Keywords: & successfully continuing the learning process, an investigation was carried out \\
\hline COVID-19 & in the Moroccan context. This survey was launched as a questionnaire with \\
\hline Distance learning & 565 participants; they are students and teachers from primary, secondary, \\
\hline Face-to-face & research questions concerning the current use of distance education during \\
\hline Solution & the COVID-19 pandemic. The results of this survey are presented in this \\
\hline Survey & $\begin{array}{l}\text { article as well as their analysis showing that solutions and alternatives must } \\
\text { be adopted in order to improve the teaching and learning process in the event } \\
\text { of a situation like COVID-19. }\end{array}$ \\
\hline
\end{tabular}

This is an open access article under the CC BY-SA license.

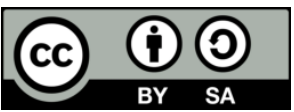

Corresponding Author:

Sara Ouahabi

Department of mathematics and computer science

Faculty of Science Ben M'Sik

Av Driss El Harti Sidi Othmane Casablanca B.P 7955, Morocco

Email: sara.ouahabi@gmail.com

\section{INTRODUCTION}

Distance education is a rapidly growing sector. This concept of training is reinforced by the advent of networks and technologies based on the internet (synchronous and asynchronous communication tools and web). It does not date from yesterday, for a hundred years, those who want it, can follow distance courses on paper or by television since its invention. However, with online education, the phenomenon is growing. Distance learning (DL) can be defined in relation to face-to-face training, intra muros, as being a formation which is characterized by space-time relocation. Learners are not required to be present in the same places and at the same time as teachers [1]. Distance learning covers several modalities: correspondence courses, elearning which is the subject of our study and resource centers. E-learning (abbreviation for "electronic Learning") is the use of computer and Internet resources to acquire knowledge from a distance. This type of learning, which is one of the facets of e-learning, is differentiated by the use of web technology. These applications and content are delivered via a computer connected to an intranet, an extranet or the internet. The contents constitute a more advanced stage than the use of the CD-Rom or the courses are given in the classroom. E-learning is a revolutionary field, a change in the field of learning. The instructions which it offers online can be provided anytime and anywhere by a very wide range of e-learning solutions such as discussion groups, virtual courses, video and audio, web chat, simulations. Given its impact on education [2]- 
[4] this type of education, which was increasingly present at the time of the crisis, has become an important issue in order to ensure pedagogical action [5], [6]. For this reason, it would be urgent to initiate a reflection on this subject.

At a time when the world is in health crisis problem due to the spread of the COVID-19 pandemic [7], and when the major part of the world population is confined, Morocco is one of the countries which imposed containment as soon as the first positive test cases were declared. Before that, Morocco had closed schools, private and public higher education establishments until further notice. In this time of health crisis, telework has obviously emerged as a solution in the majority of sectors. The situation created by confinement is without real precedent, and everyone is forced to adapt as best they can to this new situation, especially in the field of education where face-to-face teaching is undeniably the very principle on which the majority rests, if it is not the whole process of teaching in Morocco, and where the whole of the courses currently dispensed by distance. Teaching goes from face-to-face to distance learning Distance education at the time of COVID-19 (2020). The objective of this article goes in this direction. This is a field study to fully understand all aspects of this educational revolution during the coronavirus pandemic. According to our knowledge there is not enough work dissecting these changes in practices, especially in the Moroccan context and answering the following research questions, in the form of a questionnaire, in order to answer: What are the challenges of distance learning? Could distance learning replace face-to-face training? What are the obstacles preventing the use of distance learning? These are the questions that will form the basis of our analysis.

From the analysis of the results, it has been deduced that distance learning [1]-[6], shows its usefulness in the case of COVID-19 [7]. According to our findings on distance learning at the time of the coronavirus in Morocco [8], [9] and after collecting data from the various participants with web based questionnaires [10], [11], we used web technologies, to process, analyze and represent quantitative data, [12], on the use of distance learning. We deducted that distance learning offers definite possibilities for improving teaching and deserves consideration for the definition of alternative and effective solutions making it possible to overcome the constraints of distance education and self-training, by supplementing face-to-face training with good distance training that can replace face-to-face training in the event of crises. This research is divided into three parts. Firstly, a portrait of the situation in Morocco is drawn in order to grasp the growing importance of this type of learning in the world of education at the time of the crisis. Then the method adopted to identify the role of distance learning during the spread of COVID-19 in Morocco. Finally, the last parts presents the analysis, the results and discussion according to the analysis of the different solutions of online education in the case of COVID-19, that highlighted the new knowledge gathered from this research, that online training cannot replace face-to-face training but are complementary.

\section{DISTANCE EDUCATION IN NUMBERS AT THE TIME OF THE CORONAVIRUS IN MOROCCO}

Since the announcement of the spread of the coronavirus in Morocco, the government has decided to stop teaching in all educational levels from March 16, 2020. In order to show the development of the use of distance education and its usefulness during this time of crisis, we present in this section the results of two weeks after the launch of distance education. The results concerning primary and secondary education, higher education, according to a progress report drawn up by the Ministry of National Education [8] and professional training, according to the OFPPT in a progress report on its distance training system, cited by the MAP Agency [9].

Primary and secondary education offer digital resources, broadcasting of the lessons filmed on the TV stations, "Teams" service, e-takwine; higher education offer electronic platforms that allow professors to make courses and lessons available to students, filmed lessons have been broadcast on TV station. For Professional training, the distance training system launched by the office of professional training and labor promotion (OFPPT) has enabled the creation of various virtual classes, educational materials (documents, videos, and software).

\subsection{Primary and secondary education}

The total number of digital resources produced has reached 3,000 in the 15 days since the launch of the distance education operation, as part of the prevention measures taken by Morocco to deal with the spread of the coronavirus. For students who don't have internet or smartphone, it was made available to them, the broadcasting of the lessons filmed on the TV stations "Athaqafia", "Tamazight" and "Laâyoune" which made it possible to cover all levels of study, from the first year of primary to the second year of the baccalaureate. The number of lessons given via the three national TV channels reached 56 lessons per day, for a total of 730 lessons since the start of the operation, the number of lessons filmed until Wednesday, April 1, totaled around 2,600 at central, regional and provincial levels. 
To enable teachers to communicate directly with their students and organize distance learning sessions through virtual courses, which allow students to be integrated into this distance learning operation, the "Teams" service was launched on March 23. The number of virtual classes created on this platform reached 400,000, until April 1, for public establishments, with a coverage rate of 52\% of the total classes. As for private schools, the number of classes organized virtually reached 30,000 with a coverage rate of $15 \%$. It is pointed out that the number of beneficiaries of this service reached 100,000 users on April 1, noting that these Figures are increasing day by day. The training of teachers and managers of the regional academies of education and training (AREF) is also done remotely through the "e-takwine" platform, the number of beneficiaries reached 23,000 on April 1.

\subsection{Higher education}

Universities are equipped with electronic platforms that allow professors to make courses and lessons available to students with a coverage rate between $80-100 \%$, as well as the use of social networks. Since March 25, filmed lessons have been broadcast on the "Arriyadia" TV station for this category of students and which concern the bachelor cycles with 3 hours of broadcasting per day (6 lessons), to increase to 6 hours per day (12 lessons.), from Monday April 6 According to a progress report drawn up by the Ministry of National Education [8].

\subsection{Professional training}

The distance training system launched by the office of professional training and labor promotion (OFPPT) has enabled the creation of a total of 8,836 virtual classes and provided 83,356 distance training sessions, totaling 228,946 hours completed to date April 07. To support this dynamic, more than 2,600 educational materials (documents, videos, and software.) have been selected and made available to trainees via the various electronic channels and sharing platforms, and the content production operation is maintained with sustained efforts. In addition, the OFPPT launched, on 06 April 2020, an e-learning platform, dedicated to the learning of foreign languages (French, English and Spanish) which will benefit 280,000 trainees The OFPPT in a progress report on its distance training system, cited by the MAP Agency [9].

\section{METHOD}

565 students and teachers participated in the study including 321 students and 244 teachers belonging to different levels of education: primary, secondary, university and professional training cf. Table 1. The study includes $52.6 \%$ of men and $47.4 \%$ of women cf. Figure 1.565 students and teachers participated in the survey. The average age of students is 20 years and the average age of teachers is 40 cf. Figure 2.

Table 1. Distribution of participants by status

\begin{tabular}{ccccc}
\hline Participant & Primary & Secondary & University & Professional training \\
\hline Teachers & 58 & 50 & 70 & 66 \\
Students & 0 & 70 & 153 & 98 \\
\hline
\end{tabular}

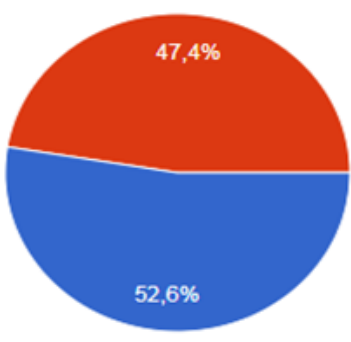

Figure 1. Gender of participants

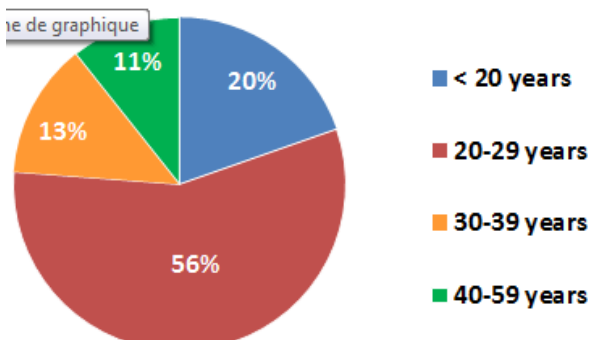

Figure 2. Participants Age

The questionnaire includes measures that are based on two sections: the first section defines the portrait of the participants (status, gender, age). The second section focuses on the use of distance learning, its type, the satisfaction of teachers and students and the various difficulties encountered. After collecting data from the various participants with web based questionnaires [10], [11], we used web technologies, to process, analyze and represent quantitative data, [12], on the use of distance learning. Knowing that the 
procedure that was followed in order to properly conduct the investigation was launched in early April 2020 when the COVID-19 virus spread. It was sent in electronic version to teachers and students through social networks and e-learrning platforms. All participants were told the objectives of the survey and the questionnaire was written in French.

\section{ANALYSIS}

\subsection{Use of distance learning}

During this survey, participants were asked about the use of distance education before the spread of the coronavirus, the results indicate that $55.1 \%$ of teachers have already used distance education to disseminate knowledge to students while $44.9 \%$ of teachers have never used distance learning cf. Figure 3. For students, the results show that $47.3 \%$ of students have never taken online training compared to $52.7 \%$ cf. Figure 4. When COVID-19 spread, 100\% of participants whether teachers or students, used distance learning to continue their learning activities.

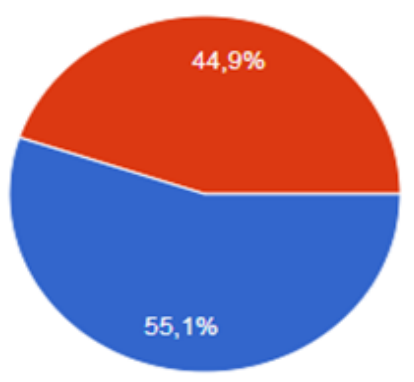

Figure 3. Using of distance learning by teachers

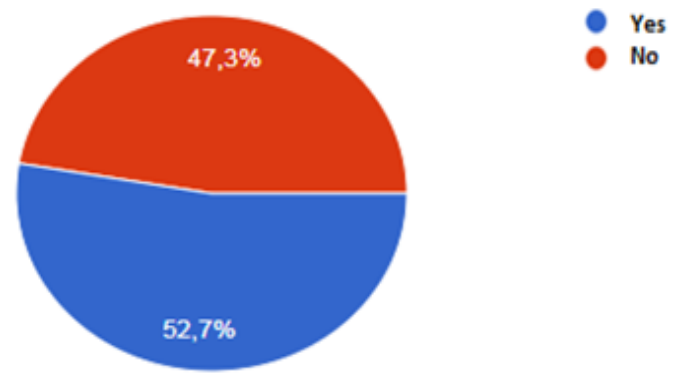

Figure 4. Monitoring of online training by students

\subsection{Type of distance learning}

Over the past few years, the increasing use of digital technologies in face-to-face or distance learning has led to the emergence of various types of courses:

a) Asynchronous learning [13] courses in which all the content and activities are made available to students who chooses when to carry them out and possibly communicates with a speaker or peers by sending messages, in this type of teaching the supports and the work to be done are published on the web, by email.

b) Synchronous learning [13] courses in which all of the content and activities are made available to students who must participate in certain teaching or exchanges at real time and according to the technological means provided for in the plateform like videoconference and audioconference.

c) Blended learning [14] online course combining synchronous and asynchronous modalities.

According to our study, the type of distance learning most used by students and teachers is hybrid, which combines synchronous and asynchronous learning with a utilization rate of $50.6 \%$, compared to $32.7 \%$ for asynchronous learning and $16.7 \%$ for synchronous learning cf. Figure 5. The results show that $62.6 \%$ of participants actually prefer the use of hybrid distance learning, as we find that just $14.7 \%$ who prefer asynchronous distance training against $22.7 \%$ who prefer synchronous training cf. Figure 6.

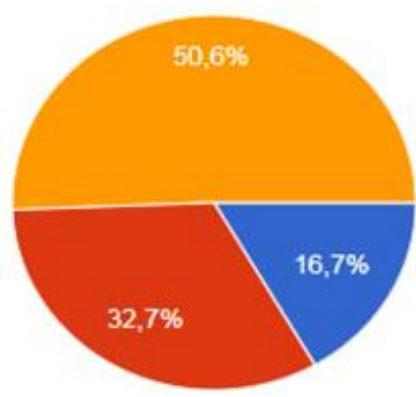

Synchronous (communicate in real time by videoconf erence, audiocorf erence...)

- Asynchronous (supports and works to be performed are published on the web, by E-mail ...)

Hybrid (both at the same time)

Figure 5. Types of training used by participants 


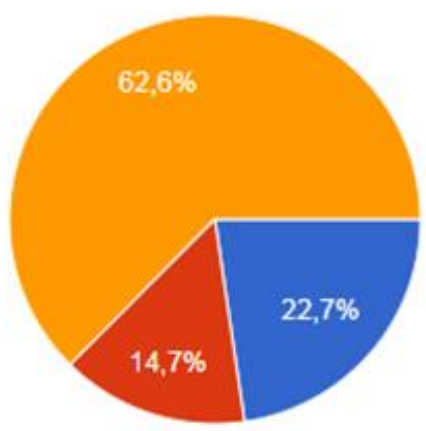

Synchronous /communicate in real time by videoconference, audiocorf erence...

Asynchronous (supports and works to be performed are published on the web, by E-mail ....)

Hybrid (both at the same time)

Figure 6. Types of training preferred by participants

\subsection{Satisfaction with distance learning}

Despite the massive use of distance learning, $51.2 \%$ of participants are not satisfied with the use of distance learning, compared to $48.8 \%$ of participants cf. Figure 7.
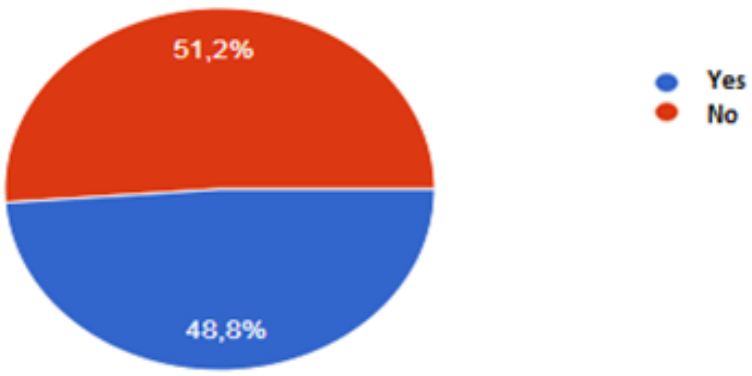

Figure 7. Satisfaction of participants

\subsection{The encountered difficulties}

During this survey, participants were asked about obstacles encountered when using distance learning, we note that $51.9 \%$ of the participants find technical difficulties (slowness of connection and problem in the computer) [15], while $17.9 \%$ of the participants are not satisfied with the quality of the educational methods (The organization of the content, Wiki, the presence of tutors) [16], while $6.8 \%$ don't master the computer tools, and 7.4\% encounter problems that come from their environment (noise), $9.3 \%$ of difficulties in terms of learner evaluation.

Among the difficulties cited by the learners cf Figure 8:

a) Technical and educational difficulties at the same time.

b)Depression due to confinement

c) Students do not have a PC
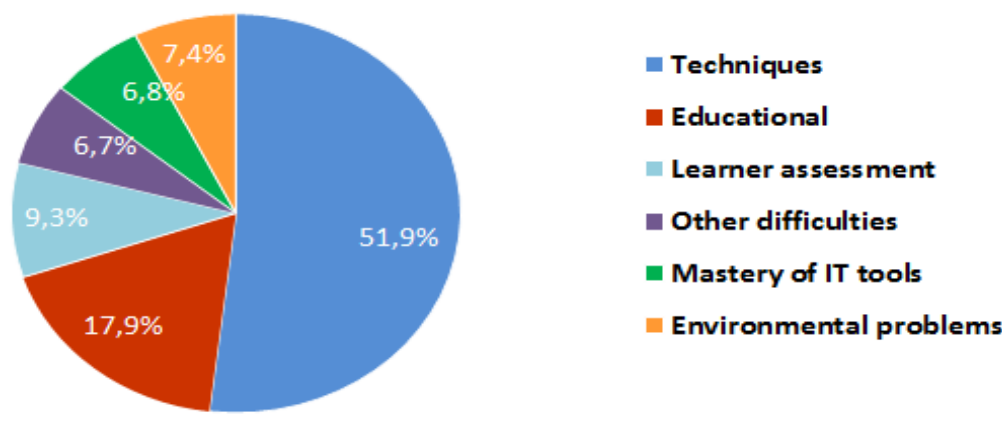

Figure 8. Difficulties encountered by participants 


\subsection{The training mode}

Concerning the participants' opinion towards the preferred training mode as being the effective learning mode to adopt after confinement due to the Coronavirus pandemic, we arrived at the following results, according to the graph above, we see that $60.2 \%$ of the participants believe that mixed training which combines distance learning and face-to-face training [17], is training that really corresponds to their needs and expectations. While $29.8 \%$ disagree and confirm that face-to-face learning is better and more effective than distance learning and $9.9 \%$ prefer purely distance learning cf. Figure 9.
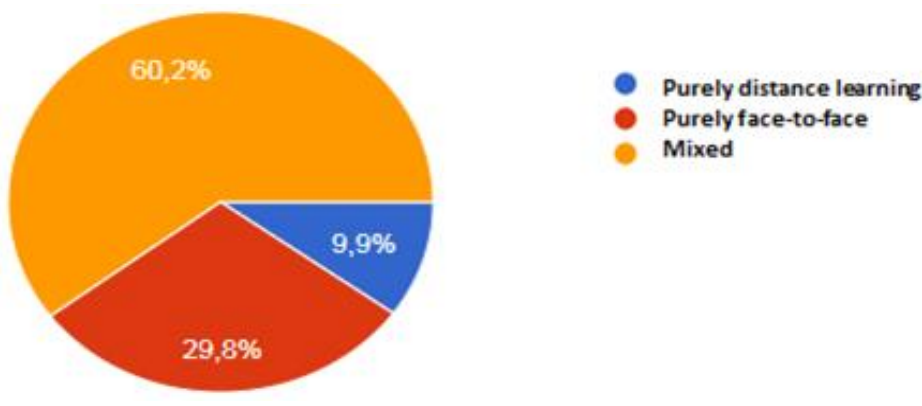

Figure 9. Preferred training after COVID-19

\subsection{Comments and suggestions}

Finally, among the suggestions and remarks offered by the different participants. That majority of students insist on using videos to understand content. Another suggestion that proposes to provide teachers and students with the necessary technical means (PC, internet connection) to ensure good distance learning. The last is that students are not satisfied with the educational content (content is not clear and the organization of the content is not consistent).

\section{RESULTS AND DISCUSSION}

This study has the goal of collecting data on the use of distance learning during the spread of COVID-19 and it sheds light on the importance of distance education through a survey intended for students and teachers belonging to different levels of education. According to the results of this research, we find that $44.9 \%$ of teachers never used distance education before the spread of the COVID-19 virus [7], and 47.3\% of students never took online training, however, following the cessation of face-to-face courses, $100 \%$ of participants use distance learning to follow their learning activities.

We can deduce that distance learning plays a very important role in filling any educational gap [3] and ensuring educational continuity during disasters that threaten education in whole world such as pandemics, wars, and climate change. However, the results show that almost half of the students and teachers have never accessed online training, they were suddenly confronted with this type of teaching, while they remained isolated for over years which left many of them in a state of confusion. In this regard, the hypothesis which structures our thinking is that recourse to distance education should not be occasional but it is necessary to develop distance education as a complement to face-to-face learning to have quality, effective, accessible distance training that can replace face-to-face training at any time.

The results of our survey also show that the most used and preferred type of online training is hybrid distance learning, which combines synchronous online education on the one hand where the teacher is in direct media contact and real-time with learners (audiography and videoconferencing) on the other hand, asynchronous online education, which makes it possible to index and make available all the resources necessary to achieve learning objectives or to develop skills in the same place. They are easily accessible, regardless of the location of the actors and the time, provided that they have a computer and multimedia accessories as well as an Internet connection. Following these results, it is important to personalize the learning by offering online courses adapted to different learners based on a mixed online education that integrates synchronous and asynchronous Web technologies [18]. Our results also indicate that 51.2\% of the participants are not satisfied with the use of e-learning, which means that the accessibility targets of Elearning are however limited by certain constraints detailed in the analysis section.

Although the statistics released by the digital report, claim that $69 \%$ of Moroccans have access to the internet at the end of 2019,60\% of Moroccan households have a computer and one in five individuals has 
a computer or a tablet, students in Morocco unfortunately do not all have internet access or a computer, let alone printers. Moreover, in families where the parents telecommute, this poses a problem since the average size of households in Morocco is 4.3, where there can be several children of school age; the situation therefore obliges to organize the distribution of working time. Use of the computer for each member of the family something that is probably not obvious. Distance education at the time of COVID-19 [7].

To remove the obstacles of online training and ensure a smooth transition to distance education, we offer the following suggestions. Distance education revolves around the computer tool, so the technical problems related to its use and maintenance cause many inconveniences, we note that $51.9 \%$ of the participants find technical difficulties, these are mainly connection problems (slow or non-existent connection, disruption of the line) which would not be favorable for example to make large downloads, follow a video online or to have sound or follow a video conference.

So to take a course online, the availability and quality of network service must be ensured because the connection problems disturb the exchanges between the protagonists not only during lessons but also during evaluations. This is all the more deplorable during synchronous sessions on the platform since they can be interrupted by the lack of connection or by a faulty connection [19]. The use of cloud computing to increase the quality of teaching and support the transformation of educational establishments by offering them scalable solutions and services while guaranteeing access to learning and resources for all stakeholders, everywhere, all the time [20], [21].

It is important to emphasize pedagogical constraints as an important factor that leads to abandonment in the context of e-learning [22], [23], since we see that $17.9 \%$ of the participants are not satisfied with the quality educational resources and methods. Several conditions are likely to favor the personalization of learning [24]-[29]. Renew methodologies and programs that have existed for years, so that they can keep pace with the changes that exist at national and international level and get in tune with the digital revolution [30]. Consider the learner's personal experiences by providing tailored training adapted to their knowledge and skills. In other words, the system must avoid offering learning content that has already been learned, but rather foster the development of new knowledge and skills by allowing the learner to define their learning outcomes in relation to specific course content and to select learning resources necessary to achieve the objectives of the course or training. Respect each learner's learning style, that is, how he processes information and his preferences in terms of learning modes and conditions by offering diverse pathways and learning resources tailored to his style. In other words, the system should offer the same training in multiple ways: textual, sound, audiovisual; synchronous, asynchronous and mixed; individualized or collaborative learning. Encourage the immediate application of new concepts learned using active teaching methods. In other words, the system must offer learning content that is built using case studies, games, simulations, problem solving, and collaborative learning. Equip the learner to apply appropriate learning strategies to different learning situations. In other words, the system allows the learner to access tools that facilitate sound management family-work-study time, including a work schedule, and tracking sheet. Provide an opportunity for the learner to interact with the content by providing exercises, practices, examples and feedback. In other words, each learning activity is designed to foster this interaction with the content; for example, all concepts are illustrated with both textual and illustrated examples. Provide relevant information and up-to-date data relevant to the learner's work or interests. In other words, the system must take into account the learning environment of the learner or his training interests in order to provide examples and activities that apply to the learner. Offer easily accessible training, at the convenience of the learner, in synchronous and asynchronous mode. Vary learning situations and build interactive content to arouse interest and motivate learners [31].

According to our study, we find that $6.8 \%$ of participants don't master the computer tool, this is a real problem for those who don't know it, for that we propose to; Provide continuous training for actors in online training to raise the level of teacher's digital culture, particularly those related to the production of digital content (courses, videos, creation of websites or digital platforms, virtual communication technologies) [32]. Generalize the teaching of "information technology" [33] to all educational establishments and encouraging teachers to produce and put digital lessons online. Allocating dedicated rooms and having the necessary digital devices (computers, projectors, cameras), taking care to equip all departments with projectors [34]. Finally, we note that $60.2 \%$ of participants believe that blended training that combines distance learning (courses in which a significant number of face-to-face sessions are replaced by online learning sessions or activities, either synchronously or asynchronously) and face-to-face learning (which refers to the time when the persons taking training are gathered in the same place with a trainer. The face-to-face training corresponds to the traditional training mode) is training that really meets their needs and expectations [17]. This answers our initial hypothesis, and highlighted the new knowledge gathered from this research, that online training cannot replace face-to-face training but are complementary. 
Compared to the literature, our article stands out for its conclusion approved by the participants that distance learning can replace face-to-face training in the event of crises. In [35] focuses more on the challenges on the other hand in [36] evokes the technical, psychic and educational concerns of the interveners during the COVID-19 period. Our article dealt with several aspects at the same time and deduced that mixed training which combines distance learning and face-to-face training is training that really corresponds to the needs of participants with respect for the wishes of the actors in terms of preferences according to the different analyzes of this paper without forgetting the avoidance of obstacles.

\section{CONCLUSION}

The study carried out, largely answered the various research questions established, via a survey invoking the different collaborators of the teaching and research field in Morocco. These questions confirm that effective and quality distance training must complement face-to-face training in order to replace the latter in the event of a crisis. Compared to earlier research, most focus on the effectiveness of distance learning in normal cases, our article is characterized by its conclusion approved by the participants that distance learning can replace face-to-face training during crises. The global crisis triggered by the coronavirus pandemic has very negative consequences affecting different economic, education, social and health fields, but like any crisis it also has a positive impact which pushes decision-makers, to learn good lessons, finding solutions and alternatives, allow not only to adapt to the current situation, but also to manage priorities and move forward with prudence and confidence. Our article shed light on several points and answered several scientific questions that could upset and help the scientific community to find important solutions that are very useful during crises or not.

\section{REFERENCES}

[1] D. J. Keegan, "On Defining Distance Education," Distance Education, vol. 1, no. 1, pp. 13-36, 1980, doi: $10.1080 / 0158791800010102$

[2] L. Lysenko, P. C. Abrami, C. A. Wade, J. P. Marsh, M. WaGioko,and E. Kiforo, "Young Kenyans' Growth in Literacy with Educational Technology: A Tale of Two Years of Implementation," International Journal of Educational Research, vol. 95, pp. 176-189, 2019, doi: 10.1016/j.ijer.2019.02.013.

[3] Y.Tsai, et al., "Learning Analytics in European Higher Education-Trends and Barriers," Computers \& Education, vol. 155, 2020, doi: 0.1016/j.compedu.2020.103933.

[4] P. Magalhães, D. Ferreira, J. Cunha, and P. Rosário, "Online vs Traditional Homework: A Systematic Review on the Benefits to Students' Performance," Computers \& Education, vol. 152, 2020, doi: 10.1016/j.compedu.2020.103869.

[5] N. Mercer, S. Hennessy, and P. Warwick "Dialogue, Thinking Together and Digital Technology in the Classroom: Some Educational Implications of a Continuing Line of Inquiry," International Journal of Educational Research, vol. 97, pp. 187-199, 2019, doi: 10.1016/j.ijer.2017.08.007.

[6] M. Misfeldt, A. L. Tamborg, J. Dreyøe, and B. B. Allsopp, "Tools, Rules and Teachers: The Relationship Between Curriculum Standards and Resource Systems when Teaching Mathematics," International Journal of Educational Research, vol. 94, pp. 122-133, 2019, doi: 10.1016/j.ijer.2018.12.001.

[7] Coronavirus disease 2019 (COVID-19): Situation Report 73, World Health Organization, 2020, [Online]. Available: https://apps.who.int/iris/handle/10665/331686.

[8] Progress report on the distance learning system, Médias24, April 2020, [Online]. Available: https://www.medias24.com/bilan-d-etape-du-dispositif-d-enseignement-a-distance-9105.html/. (Accessed 30 may 2020).

[9] Vocational Training: the OFPPT Draws Up an Initial Assessment, EcoActu, April 2020, [Online]. Available: https://www.ecoactu.ma/formation-professionnlle-ofppt/. (Accessed 30 may 2020).

[10] J. E. Pitkow and M. M.Recker, "Using the Web as a Survey Tool: Results from the Second WWW User Survey," Computer Networks and ISDN Systems, vol 27, no. 6, pp. 809-822, 1995, doi: 10.1016/0169-7552(95)00018-3.

[11] B. K. Kaye and T. J. Johnson, "Research Methodology: Taming the Cyber Frontier. Techniques for Improving Online Surveys," Social Science Computer Review, vol. 17, no. 3, pp. 323-337, 1999, doi: $10.1177 / 089443939901700307$.

[12] G. Haughton and A. Stevens, "Quantitative Data Processing and Analysis," in Practical Research and Evaluation: A Start-to-Finish Guide for practitioners, London, United Kingdom: SAGE Publications Ltd, 2010, pp. 191-218.

[13] Gérin-Lajoie, S., \& Potvin, C. "Evolution of distance education in a bimodal university," Distances and Knowledge, vol. 9, no. 3, pp. 349-374, 2011.

[14] Lakhal, S., \& Power, M. "Online training in post-secondary education in Quebec: proposal for a typology of courses,” In Beyond our borders, pp. 104-106, Québec: CIRTA, 2016.

[15] H. Karal, A. Çebi, and M. Pekşen, "Student Opinions About the Period of Measurement and Evaluation in Distance Education: the Difficulties," Procedia-Social and Behavioral Sciences, vol. 9, pp. 1597-1601, 2010, doi: 10.1016/j.sbspro.2010.12.371. 
[16] H. Kanuka, "Interaction and the Online Distance Classroom: Do Instructional Methods Effect the Quality of Interaction?," Journal of Computing in Higher Education, vol. 23, no. 2-3, pp. 143-156, 2011, doi: 10.1007/s12528-011-9049-4.

[17] S. S. Jaggars, "Choosing Between Online and Face-to-Face Courses: Community College Student Voices," American Journal of Distance Education, vol. 28, no. 1, pp. 27-38, 2014, doi: 10.1080/08923647.2014.867697.

[18] G. M. Johnson, "Synchronous and Asynchronous Text-Based CMC in Educational Contexts: A Review of Recent Research," TechTrends, vol. 50, no. 4, pp. 46-53, 2006, doi: 10.1007/s11528-006-0046-9.

[19] G. Falloon, "Making the Connection: Moore's Theory of Transactional Distance and Its Relevance to the Use of a Virtual Classroom in Postgraduate Online Teacher Education," Journal of Research on Technology in Education, vol. 43, no. 3, pp. 187-209, 2011, doi: 10.1080/15391523.2011.10782569.

[20] S. Ouahabi, A. Eddaoui, H. Labriji, E. Benlahmar, and K. El Guemmat, "Using IMS LD Specification for Elearning in the Cloud Computing," International Journal of Information and Education Technology, vol. 5, no. 11, pp. 860-864, 2015, doi: 10.7763/IJIET.2015.V5.627.

[21] S. Ouahabi, A. Eddaoui, H. Labriji, E. Benlahmar, and K. El Guemmat, "Implementation of a Novel Educational Modeling Approach for Cloud Computing," International Journal of Emerging Technologies in Learning, vol. 9, no. 6, pp. 49-53, 2014, doi: 10.3991/ijet.v9i6.4153.

[22] D. Hillmayr, L. Ziernwald, F. Reinhold, S. I. Hofer, and K. M. Reiss, "The Potential of Digital Tools to Enhance Mathematics and Science Learning in Secondary Schools: A Context-Specific Meta-Analysis," Computers \& Education, vol. 153, 2020, doi: 10.1016/j.compedu.2020.103897.

[23] H. Fjørtoft, "Multimodal Digital Classroom Assessments," Computers \& Education, vol. 152, 2020, doi: 10.1016/j.compedu.2020.103892.

[24] Center for Educational Research and Innovation [CERI] of the Organization for Economic Co-operation and Development [OCDE]. Personalize teaching. Paris, France: OCDE Publishing, 2006.

[25] Pernin, J.-P. and Lejeune, A. Technology-Powered Learning Devices: Towards Scenario-Based Engineering [electronic version]. In Proceedings of the conference TICE 2004 (p. 407-414). Compiègne, France: University of Technology of Compiègne. Retrieved from the personal website of the first author at the Grenoble Institute of Computer Science and Applied Mathematics, Research-Publications section, 2004.

[26] Sauvé, L. "Training and adaptation to new technologies," In Conference Have the factors of social inclusion changed 2001.

[27] Sauvé, L. "Online distance learning: pedagogical and technological analysis," Communication presented at the congress From distance education to online access to knowledge. Nanterre, France, 2004.

[28] Sauvé, L., \& Wright, A. "Personalized learning for online training: A decade of francophone research," Learners in midlife: Graduate education and workplaces in Canada, pp. 161-197, 2008.

[29] Vanderspelden, J. APP : to individualize is not to personalize or learn to train yourself! Retrieved from the website of the Association for the promotion of the APP label and for the national animation of the network of personalized pedagogy workshops, http://site.app.tm.fr/publications/pdf/vds.pdf, 2004.

[30] A. D. Thompson, D. A. Schmidt, and Niki E. Davis, "Technology Collaboratives for Simultaneous Renewal in Teacher Education," Educational Technology Research and Development, vol. 51(1), pp. 73-89, 2003, doi: 10.1007/BF02504519.

[31] F. Henri, "Distance Learning and Computer-Mediated Communication: Interactive, Quasi-Interactive or Monologue?," Computer Supported Collaborative Learning, vol. 128, pp. 145-161, 1995, doi: 10.1007/978-3-64285098-1_8.

[32] Cho, S. K., \& Berge, Z. L. Overcoming barriers to distance training and education. USDLA Journal, 16(1), 16-34, 2002.

[33] W. S. Luan, H. A. Jalil, A. F. M. Ayub, K. A. Bakar, and T. S. Hong "Teaching a Discrete Information Technology Course in a Constructivist Learning Environment: Is It Effective for Malaysian Pre-Service Teachers?," The Internet and Higher Education, vol. 6, no. 2, pp. 193-204, 2003, doi: 10.1016/S1096-7516(03)00025-3.

[34] Ş. Karadeniz, "Flexible Design for the Future of Distance Learning," Procedia-Social and Behavioral Sciences, vol. 1, no. 1, pp. 358-363, 2009, doi: 10.1016/j.sbspro.2009.01.066.

[35] H. Bachiri and R. Sahli, "The Need of Distance Learning in the Wake of COVID-19 in Morocco: Teachers' Attitudes and Challenges in the English Foreign Language Instruction," International Journal of Language and Literary Studies, vol. 2, no. 3, pp. 240-256, 2020, doi: 10.36892/ijlls.v2i3.326.

[36] O. Dardary, J. Daaif, M. Tridane, and S. Belaaouad, "Distance Learning in the Age of COVID-19: Between Perspective and Reality." International Journal of Engineering Applied Sciences and Technology, vol. 5, no. 5, pp. 46-52, 2020, doi: 10.33564/IJEAST.2020.v05i05.008. 